\title{
FATAL EFFECTS OF HYPERKALEMIA
}

Mohammed Sabiullah¹, Rahmathunnisa², Vydehi Veeramalla3 ${ }^{3}$ R. Babu Rao ${ }^{4}$, B. Sadhana ${ }^{5}$

\section{HOW TO CITE THIS ARTICLE:}

Mohammed Sabiullah, Rahmathunnisa, Vydehi Veeramalla, R. Babu Rao, B. Sadhana. "Fatal Effects of Hyperkalemia". Journal of Evolution of Medical and Dental Sciences 2015; Vol. 4, Issue 76, September 21;

Page: 13267-13273, DOI: 10.14260/jemds/2015/1908

ABSTRACT: Hyperkalemia is one of the few potentially lethal electrolyte disturbances. Prompt recognition and treatment of severe hyperkalemia are expected to save lives. Electrocardiographic manifestations of hyperkalemia vary from the classic sine-wave rhythm, which occurs in severe hyperkalemia, to nonspecific repolarization abnormalities seen with mild elevations of serum potassium. We present a case of hyperkalemia and review of causes of hyperkalemia is presented, examining the electrophysiological and electrocardiographic changes that occur as serum potassium levels increase.

KEYWORDS: Electrocardiography, Hyperkalemia.

CASE REPORT: A 45 yrs., old woman was admitted in the morning with chief complaint of vomiting which is non-projectile, yellowish in color with black streaks since 4 days. Sudden onset of weakness of both lower limbs more than upper limbs and dysarthria since 1 day. Incontinence of bowel and bladder present. Oral mucosal bleeding is present. Her medical history included hematuria, burning micturition, renal calculi which subsided on treatment. Her medical history denied diabetes mellitus, hypertension. Her blood pressure was $140 / 80 \mathrm{~mm}$ of $\mathrm{Hg}$ with pulse rate of 92 beats/min. She was breathing 14 times/min with an oxygen saturation of $99 \%$. On cardiovascular examination, heart sounds were audible. Her lung fields were clear to auscultation bilaterally, and results of the abdominal examination were normal. The extremities were without cyanosis or edema. Neurologically, she was alert and oriented, with dysarthria. Tone in upper limbs was normal but hypotonia in both lower limbs. Power in both upper limbs was $3 / 5$ and lower limbs was $0 / 5$ with absent deep tendon reflexes. Orthostatic hypotension was absent. Graded sensory loss in both upper limbs and lower limbs for pain and temperature. Cerebellum cannot be tested. She was kept on Inj Monocef, Intravenous fluids - NS, RL, DNS, Inj Tranexa, Inj Ethamsylate, Inj Optineuron, Inj Methylprednisone, Inj Pantoprazole.

Her biochemical analysis revealed urea $144 \mathrm{mg} / \mathrm{dl}$, creatinine $7.2 \mathrm{mg} / \mathrm{dl}$ and sodium $124 \mathrm{meq} / \mathrm{l}$ and potassium $10.5 \mathrm{meq} / \mathrm{l}$.USG Abdomen revealed in right kidney $5 \mathrm{~mm}$ multiple hyper echoic picture suggesting Renal calculi. Hemoglobin was $6 \mathrm{gms} \%$. Pancytopenia was observed. Results of multiple 12lead electrocardiograms revealed tall tented $T$ waves in Lead I, II, $V_{2}$ to $V_{6}$, which led to a diagnosis of Hyperkalemia (Fig. 1). Before the patient underwent emergent dialysis, death took place in the night.

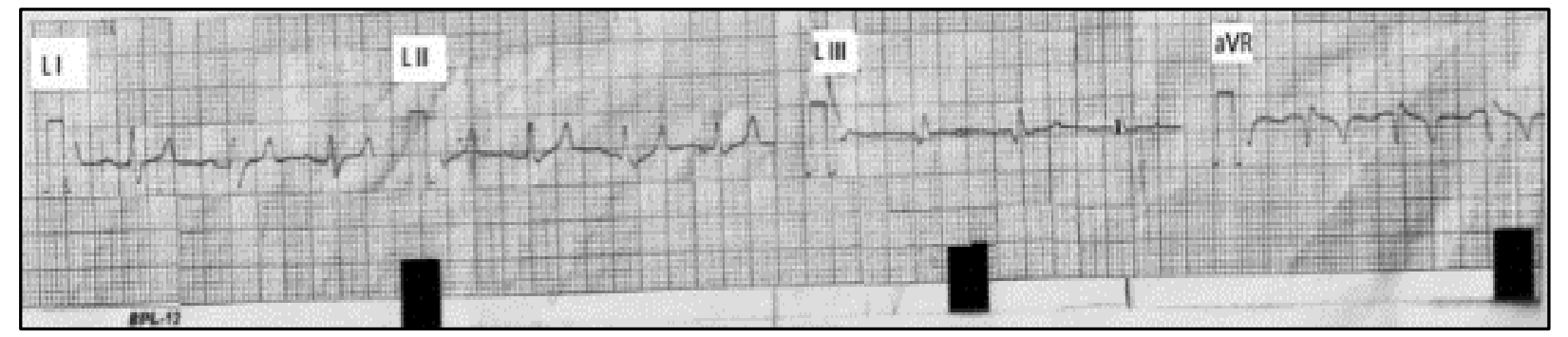

Fig. 1a: Lead I, II, III, aVR 


\section{CASE REPORT}

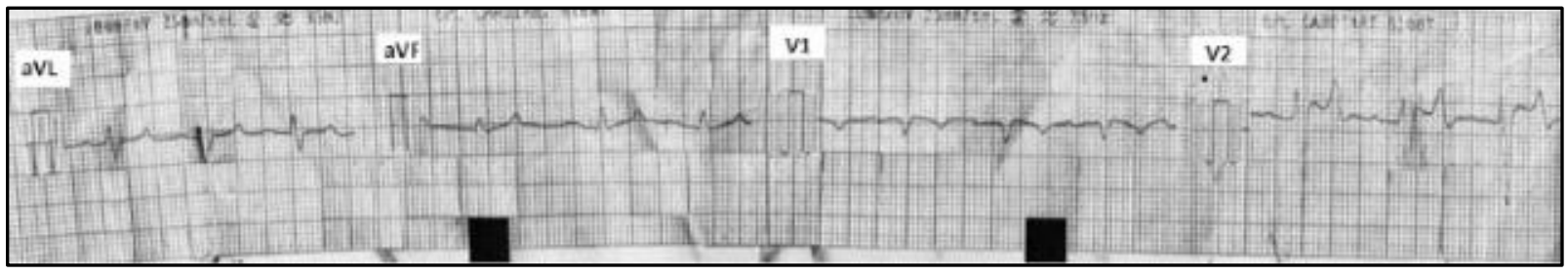

\section{Fig. 1b: aVL, aVF, $V_{1}, V_{2}$}

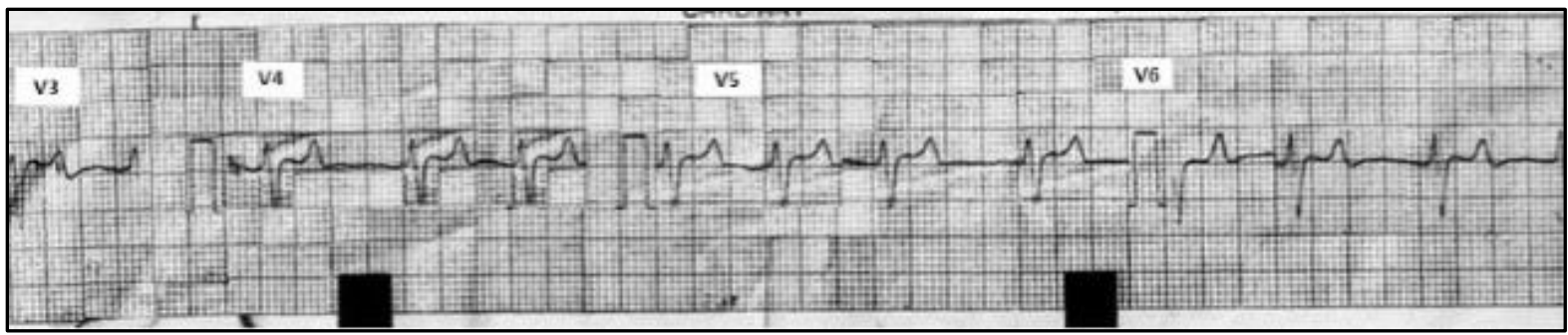

Fig. 1c: $V_{3}, V_{4}, V_{5}, V_{6}$

\section{DISCUSSION:}

Hyperkalemia: An increase in the serum potassium level above upper limit of the normal $(>5.5$ $\mathrm{mEq} / \mathrm{L}$ ) is termed hyperkalemia. The ECG findings make their Appearance when potassium level rises beyond $6.0 \mathrm{mEq} / \mathrm{L}$.

It is not necessary to have ECG changes in all patients with hyperkalemia.

Causes of Hyperkalemia: Inadequate excretion

\section{A. RENAL FAILURE (UREMIA).}

- Acute renal failure.

- Chronic renal failure.

- Renal tubular disorders.

\section{B. ADRENAL INSUFFICIENCY.}

- Hypoaldosteronism

- Addison's disease

\section{POTASSIUM SPARING DIURETICS.}

- Spironolactone

- Triameterene

- Amiloride

\section{A. SHIFT OF POTASSIUM FROM TISSUES INTO CIRCULATION.}

- Crushed muscles.

- Hemolysis.

- Internal bleeding. 


\section{B. DRUGS}

- Succinylcholine.

- Digitalis poisoning may cause rise in $\mathrm{K}^{+}$if potassium sparing diuretics are being used.

- Beta-adrenoreceptor antagonists.

C. Acidosis.

D. Hyperosmolality.

E. Insulin deficiency.

F. Hyperkalemic periodic paralysis.

\section{Excessive potassium intake in the form potassium salts or fruit juices.}

\section{Electrocardiographic Manifestations-Pathogenesis and Correlation with Potassium Levels} (Fig. 2 A to E).

As the extracellular $\mathrm{K}^{+}$further increases, resting membrane potential progressively decreases Fig. 2, the decrease in the rate of depolarization of action potential slows intra ventricular conduction and increases the duration of QRS complex. These changes are present at serum $\mathrm{K}^{+}$levels of $6.5 \mathrm{mEq} / \mathrm{L}$ or more. Where $\mathrm{K}^{+}$level exceeds $7.0 \mathrm{mEq} / \mathrm{L}$, the amplitude of $\mathrm{P}$ wave decreases and the duration of $\mathrm{P}$ wave increases because of slow conduction in the atria. The P-R interval is frequently prolonged as a result of slow AV conduction. The $\mathrm{P}$ waves are usually not seen when serum potassium level exceeds $8.0 \mathrm{mEq} / \mathrm{L}$ but QRS complexes are seen (Sine-wave appearance Fig. 2B indicating that excitability of ventricular fibers is retained even at high $\mathrm{K}^{+}$levels. The secondary ST-T changes may be seen and are due to delayed intraventricular conduction.

Ectopic ventricular rhythms, such as extra systoles, tachycardia, flutter and fibrillation may also be encountered in the advanced stages of hyperkalemia Ventricular arrhythmias presage terminal ventricular standstill.

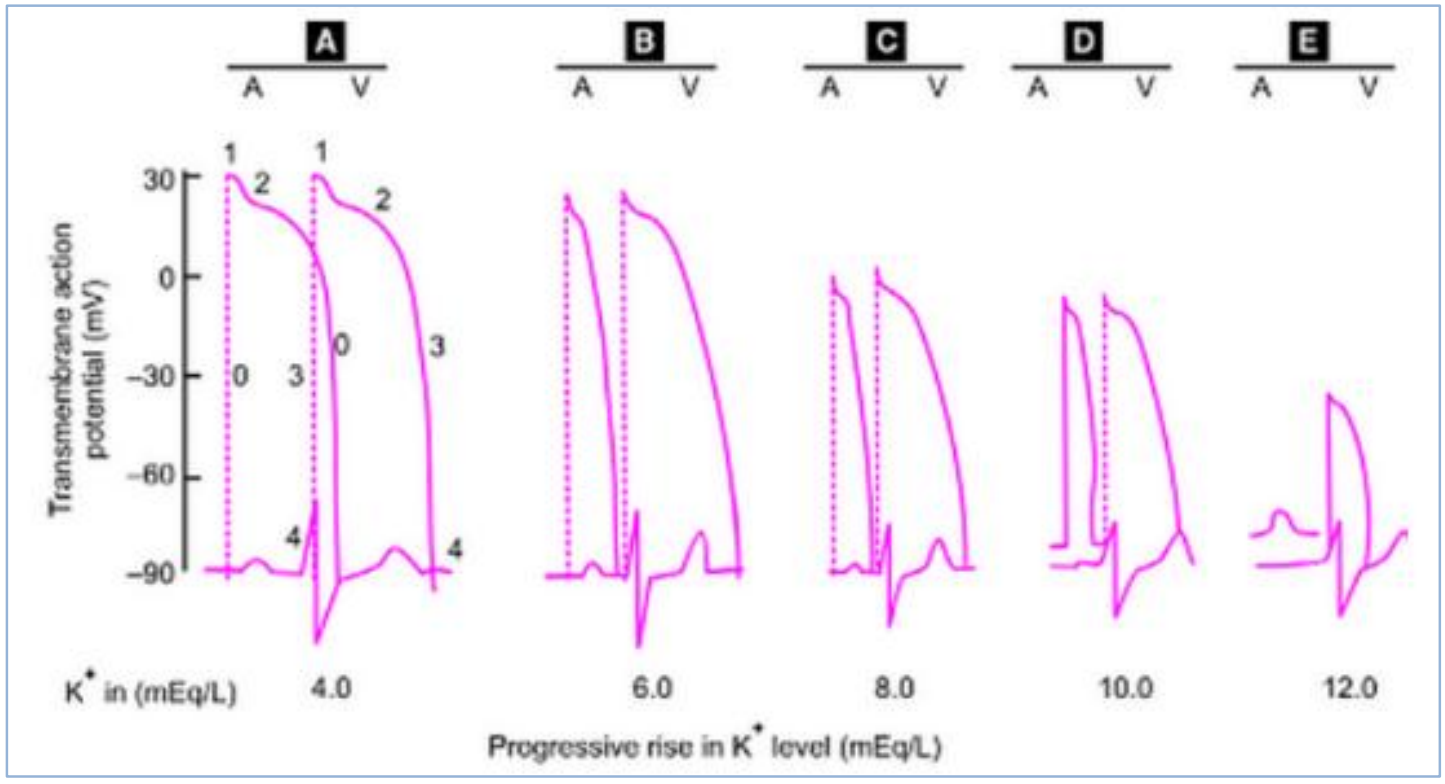


Figs. 2 A to E: The effect of hyperkalemia on action potential curve: atrial (A) and ventricular (V). An atrial (A) and ventricular (V) action potential curves are superimposed on ECG deflections (diagram). The vertical axis represents transmembrane potential (mv) and horizontal axis represents the extracelular $\mathrm{K}^{+}$in $\mathrm{mEq} / \mathrm{L}$. The various phases $(0,1,2,3,4)$ of action potential curve are depicted in (A). The rate of depolarization of the action potential is indicated in AP by the broken vertical lines. The decreasing space between dashes indicating a slowing of upstroke velocity due to slowing of rate of depolarization. The slowest upstroke is shown by a continuous line (atrial AP in D and ventricular AP in E). Note the decreasing upstroke velocity and increasing duration of the ORS complex with increasing levels of $\mathrm{K}^{+}$indicated by arrow. In (A) and (B) the atrial and ventricular AP have same amplitude of transmembrane resting potential, whereas in (C) and (D), the transmembrane resting potential of atrial AP is less negative than that of ventricular AR and the amplitude of the atrial AP is lower than that of corresponding ventricular AP. AP = Action potential curve.[1]

\section{Effects of hyperkalaemia on the ECG:}

\section{Serum potassium $>5.5 \mathrm{mEq} / \mathrm{L}$ is associated with repolarization abnormalities:}

- Peaked T waves (usually the earliest sign of hyperkalaemia).

Serum potassium $>6.5 \mathrm{mEq} / \mathrm{L}$ is associated with progressive paralysis of the atria:

- P wave widens and flattens.

- PR segment lengthens.

- P waves eventually disappear.

Serum potassium $>7.0 \mathrm{mEq} / \mathrm{L}$ is associated with conduction abnormalities and bradycardia:

- Prolonged QRS interval with bizarre QRS morphology.

- High-grade AV block with slow junctional and ventricular escape rhythms.

- Any kind of conduction block (bundle branch blocks, fascicular blocks).

- Sinus bradycardia or slow AF.

- Development of a sine wave appearance (a pre-terminal rhythm).

Serum potassium level of $>9.0 \mathrm{mEq} / \mathrm{L}$ causes cardiac arrest due to:

- Asystole.

- Ventricular fibrillation.

- PEA with bizarre, wide complex rhythm.

In individual patients, the serum potassium level may not correlate closely with the ECG changes. Patients with relatively normal ECGs may still experience sudden hyperkalaemic cardiac arrest. $[2,3,4,5,6,7,8]$

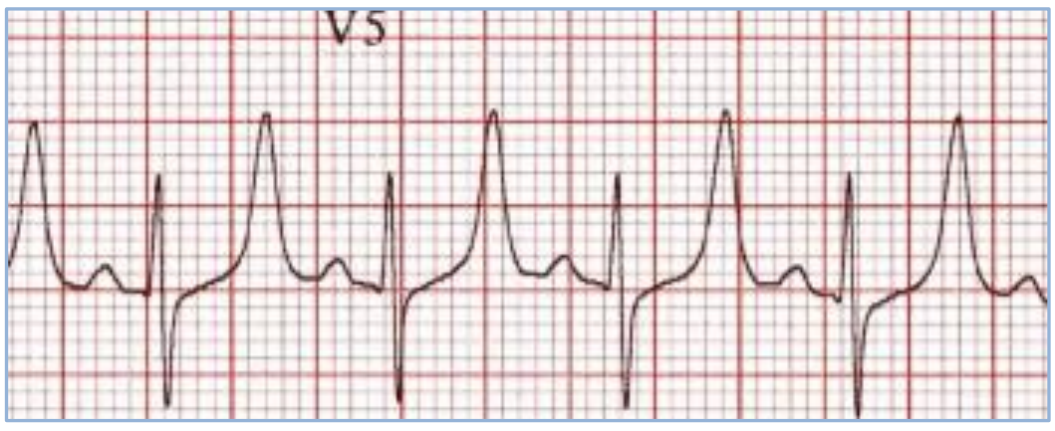

Fig. 3: Peaked T waves 


\section{CASE REPORT}

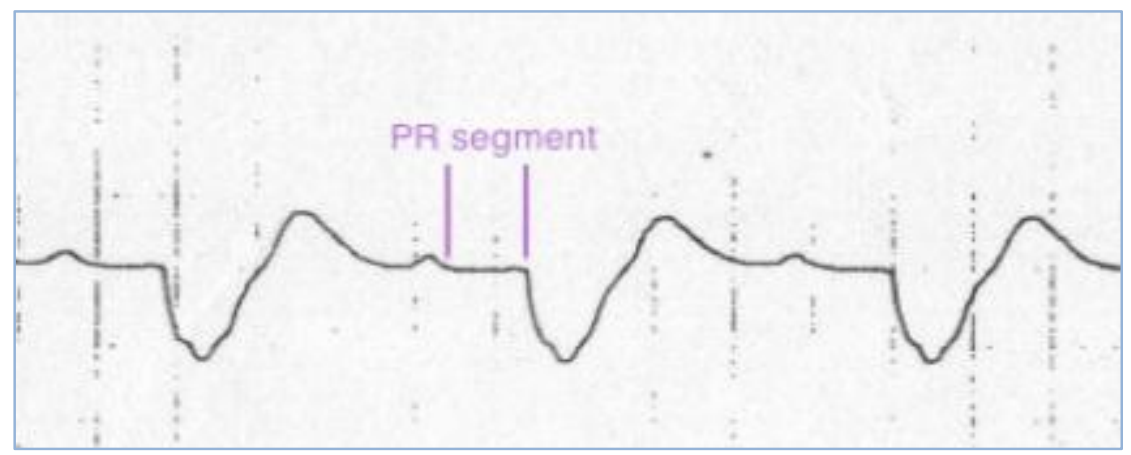

Fig. 4: Prolonged PR Segment

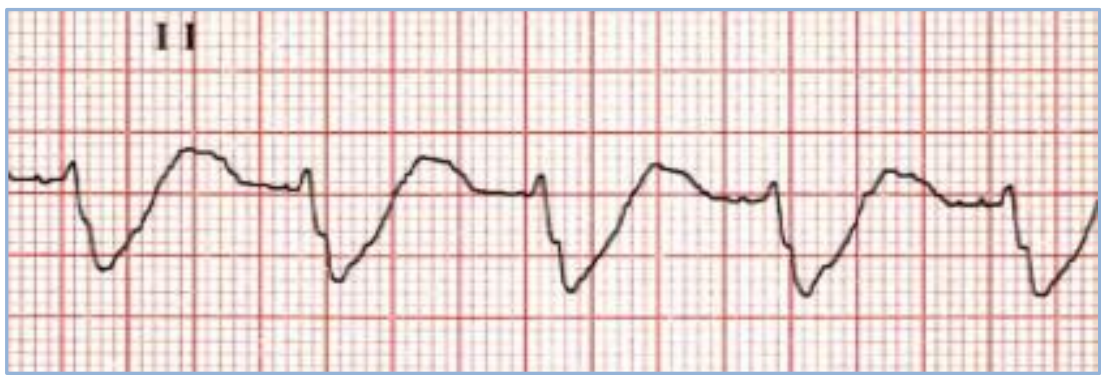

Fig. 5: Loss of P Waves

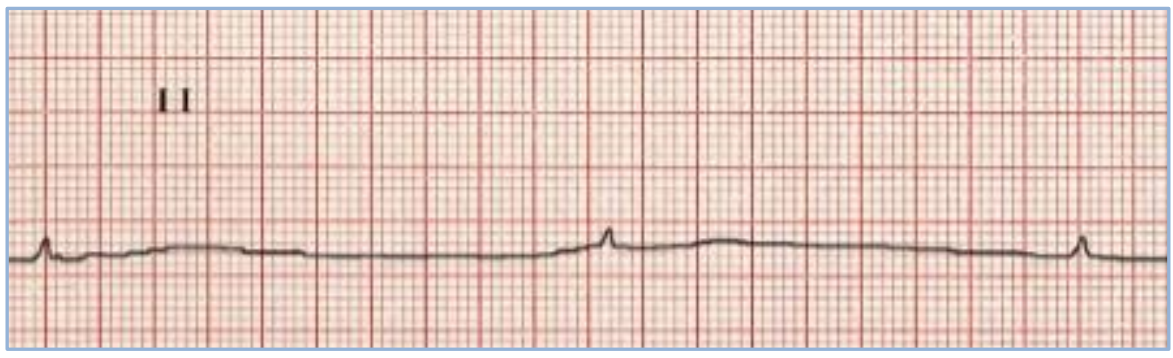

Fig. 6: Bradycardia

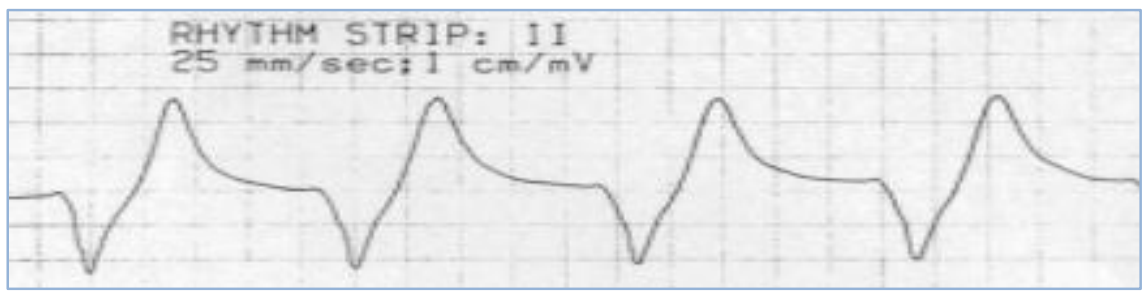

Fig. 7: Sine Wave 


\section{CASE REPORT}

Kidney disease and Hyperkalemia: As GFR declines, serum potassium levels increase as potassium filtration and secretion fall. When aldosterone or other kaliuretic factors fail to maintain potassium homeostasis, extracellular $\left[\mathrm{K}^{+}\right]$may rise until it reaches a level sufficient to produce a sustained increase in renal potassium excretion.

Risk of mortality with hyperkalemia: There were 6996 patients (2.8\%) that died within one day of a blood draw when potassium levels were recorded. The risk of hyperkalemia is increased with CKD, and its occurrence increases the odds of mortality within one day of the event. These findings underscore the importance of this metabolic disturbance as a threat to patient safety in CKD.[9]

Flaccid Motor Paralysis Induced by Hyperkalemia: Most common neurological manifestation in hyperkalemia is ascending quadriparesis or quadriplegia with diminished or absent reflexes as in this case. The serum potassium concentration leading to hyperkalemic paralysis ranged from 7.0 to 11.2 $\mathrm{mEq} / \mathrm{L}$ with a mean of $9.0 \mathrm{mEq} / \mathrm{L}$.

The mechanism of secondary hyperkalemic paralysis is unclear the weakness has been attributed to abnormalities at various locations in the motor axis, including muscle, nerve and neuromuscular junction. [10]

\section{REFERENCES:}

1. S. N. Chugh, Textbook of Clinical Electrocardiography: For Postgraduates, Resident Doctors and Practicing physicians: New Delhi; 2012. 3rd Edition, page 548, chapter46, Electrolytes and the Heart.

2. Mattu A, Brady W. ECGs for the Emergency Physician 2, BMJ Books 2008.

3. Cameron P, Jelinek G, Kelly AM, Murray L, Brown AFT. Textbook of Adult Emergency Medicine. Elsevier 2009

4. Ganong, WF. Review of Medical Physiology (22nd edition). Lange / McGraw-Hill 2005.

5. Hampton, JR. The ECG in Practice (5th edition), Churchill Livingstone 2008.

6. Phibbs BP. Advanced ECG: Boards and Beyond (second edition). Elsevier 2006.

7. Slovis C, Jenkins R. ABC of clinical electrocardiography: Conditions not primarily affecting the heart. BMJ. 2002 Jun 1; 324(7349):1320-3. Review. PMID: 12039829.

8. Wagner, GS. Marriott's Practical Electrocardiography (11th edition), Lippincott Williams \& Wilkins 2007.

9. Lisa M. Einhorn, BS, Min Zhan, PhD, Van Doren Hsu, Pharm D, Lori D. Walker, BS, Maureen F. Moen, BS, Stephen L. Seliger, MD, Matthew R. Weir, MD, and Jeffrey C. Fink, MD. The frequency of hyperkalemia and its significance in chronic kidney disease, Archives of Internal Medicine. 2009 Jun 22; 169(12):1156-62.

10. Evers S, Engelien A, Karsch V, Hund M (1998) Secondary Hyperkalaemic paralysis. Journal of Neurol Neurosurg Psychiatry 64:249-252. 


\section{CASE REPORT}

\section{AUTHORS:}

1. Mohammed Sabiullah

2. Rahmathunnisa

3. Vydehi Veeramalla

4. R. Babu Rao

5. B. Sadhana

\section{PARTICULARS OF CONTRIBUTORS:}

1. Associate Professor, Department of Biochemistry, Osmania Medical College, Koti, Hyderabad, Telangana.

2. Assistant Professor, Department of Opthalmology, Gandhi Medical College, Koti, Secunderabad, Telangana.

3. Resident Specialist, Department of Biochemistry, Osmania Medical College, Koti, Hyderabad, Telangana.

FINANCIAL OR OTHER COMPETING INTERESTS: None
4. Assistant Professor, Department of Biochemistry, Osmania Medical College, Koti, Hyderabad, Telangana.

5. Biochemist (Gazetted), Department of Biochemistry, Osmania Medical College, Koti, Hyderabad, Telangana.

\section{NAME ADDRESS EMAIL ID OF THE CORRESPONDING AUTHOR:}

Dr. Mohammed Sabiullah,

Ho. No. 12-11-1697,

Ambernagar, Secunderabad-500044.

E-mail: mohammadsabiullah@yahoo.com

Date of Submission: 04/09/2015.

Date of Peer Review: 05/09/2015.

Date of Acceptance: 15/09/2015.

Date of Publishing: 21/09/2015. 